\title{
As contribuições da teoria histórico-cultural para a atuação em classes multisseriadas
}

\author{
The contributions of the historical-cultural theory to the performance \\ in multiseriated classes
}

Suany Rodrigues da Cunha ${ }^{1}$

\section{RESUMO}

Este texto tem por objetivo apresentar uma reflexão sobre o papel do professor como organizador do meio social educativo em classes multisseriadas. Para este artigo, demandou-se uma pesquisa bibliográfica pautada na teoria histórico-cultural. Os resultados da pesquisa apontam que a teoria histórico-cultural pode propiciar o entendimento do homem como um ser histórico que se constrói através de suas relações com meio natural e social, no processo de trabalho (transformação da natureza), em um sistema dinâmico, contraditório e dialético, que ao longo de seu processo de formação está sempre produzindo conhecimentos e se apropriando da cultura. A educação é parceira nessa produção e sistematização de conhecimento, à medida em que a escola assume o papel de intervir no processo de formação humana e das Funções Psicológicas Superiores, o que repercute na constituição das qualidades humanas. Para isso, demanda a organização do ambiente social do aluno, o professor ao assumir essa função deverá ter intencionalidade, planejamento e reflexão (intervenção) para promover o desenvolvimento psíquico (apreensão de conhecimento) dos alunos. Isso, no caso das classes multisseriadas, pode operar na otimização de possibilidades concretas para se trabalhar com alunos de várias séries, distintos níveis de aprendizagem, diferentes idades e que desenvolvem o ensino e aprendizagem em um

\begin{abstract}
This text aims to present a reflection on the role of the teacher as an organizer of the educational social environment in multi-grade classes. For this article, a bibliographical research based on the historical-cultural theory was demanded. The results of the research show that the historical-cultural theory can provide the understanding of man as a historical being that, if built through his relations with natural and social environment, in the work process (transformation of nature), in a dynamic, contradictory and dialectical system that throughout its formation process is always producing knowledge and appropriating the culture. The education is a partner in this production and systematization of knowledge, as the school assumes the role of intervening in the process of human formation and Superior Psychological Functions, which has repercussions on the constitution of human qualities. For this demands the organization of the student's social environment, the teacher, when assuming this function, must have intentionality, planning and reflection (intervention) to promote psychic development apprehension knowledge of students. This, in the case of multi-grade classes, can operate in the optimization of concrete possibilities to work with students of various grades, different levels of learning, different ages and who develop teaching and learning in the same space and at the same time. Thus, integrating diversity, the conceptions and the educational practices that must be thought to educate and value the
\end{abstract}

\footnotetext{
${ }_{1}^{1}$ Mestre em Educação pela Universidade Federal do Pará (2016). Professora do Instituto Federal de Educação, Ciência e Tecnologia do Amapá. ORCID: https://orcid.org/0000-0001-9816-4895. Email: suany.cunha@ifap.edu.br.
} 
mesmo espaço e ao mesmo tempo. Assim, integrando a diversidade, as concepções e as práticas educativas que devem ser pensadas para educar e valorizar o indivíduo constituído de direito que merece ser reconhecido em sua identidade.

PALAVRAS-CHAVE: Teoria históricocultural. Papel do professor. Organizador do meio social educativo. Classes multisseriadas. individual constituted by law that deserves to be recognized in his identity.

KEYWORDS: Historical-cultural theory. Teacher's role. Organizer of the educational social environment. Multiseriate classes.

\section{Introdução}

Este artigo é fruto do aprimoramento dos saberes apreendidos na disciplina Implicações pedagógicos da teoria histórico-cultural, do Programa de Pós-Graduação em Educação, da Universidade Federal do Pará. Visa apresentar uma reflexão sobre o papel do professor como organizador do meio social educativo em classes multisseriadas.

O trabalho pedagógico em classes multisseriadas consiste na especificidade de desempenhar a lógica de trabalho e de relações pautadas na diversidade, tem representatividade significante nas escolas, em espaços não urbanos. Permeiamse a partir de conjunturas sociais, educacionais, históricas e culturais de cada ser humano que compõe o universo heterogêneo, dentro de uma sala de aula com alunos de várias séries, distintos níveis de aprendizagem, diferentes idades e que desenvolvem o ensino e aprendizagem em um mesmo espaço e ao mesmo tempo.

As classes multisseriadas constituem grande parte da realidade das escolas do campo, assim, os elementos simbólicos que fazem parte da identidade pluralizada e dos saberes dos sujeitos estão materializados no espaço onde habitam, em suas práticas sociais e nos modos de vida adaptados através da relação com a floresta, a água e a terra. Além da complexidade dos processos históricos, das singularidades de formação da cultura e da heterogeneidade humana constituída por caboclos, etnias indígenas, quilombolas, agricultores, pescadores, entre outros povos. O que consequentemente repercute nas crenças, nos valores, no simbolismo e, acima de tudo, na subjetividade que privilegia vínculos identitários e de pertencimento. 
Nessa constante é preponderante pensar nas especificidades da aprendizagem na escola, em sua articulação com o saber científico e com o saber dos seus elementos de pertencimento social e cultural, ou seja, nos saberes que o aluno traz em sua constituição. Logo, necessita-se de uma formação que propicie o acesso aos conhecimentos fundamentais para o desenvolvimento da capacidade humana de interação e de criticidade em suas relações sociais, frente ao sistema capitalista.

Um processo que necessita de uma concepção de educação, de homem e de sociedade, para visualizar o papel que a escola desempenha no desenvolvimento humano, o que incide na relação entre aprendizagem e desenvolvimento e um norte que irá referenciar a análise da realidade. É no seio desse entendimento que a teoria histórico-cultural apresenta elementos para o desenvolvimento das funções complexas do pensamento, dimensionando o papel histórico e cultural na constituição do homem.

O processo educativo constituído de visões e de leituras de mundo, pautado em uma concepção de educação e de homem que emerge do contexto histórico, que se desenvolve e se aperfeiçoa nas dinâmicas sociais, culturais e políticas, suscita desafios a quem desenvolve pesquisa. Nesse sentido, o estudo deve reconhecer o saber acumulado na história humana que se cria e se recria, e investir no interesse em aprofundar as análises desse processo histórico-cultural, contribuindo para avançar nas novas descobertas em favor do trabalho enquanto atividade que transforma o mundo e a si mesmo.

Diante disso, este texto tem por base os pressupostos da teoria históricocultural, busca apreender suas contribuições para o processo de ensinar e aprender, em especial, sobre o papel do professor como organizador do ambiente social do aluno, em classes multisseriadas. A metodologia adotada para concretizar esta investigação é centrada em uma pesquisa bibliográfica, por compreender que "a principal finalidade da pesquisa bibliográfica é levar o pesquisador a entrar em contato direto com obras, artigos ou documentos que tratem o tema em estudo" (OLIVEIRA, 2010, p. 69). A escolha desse tipo de pesquisa se dá por compreender que as fontes a serem pesquisadas já são reconhecidamente do domínio científico. 


\section{0 histórico e o cultural como eixos centrais para a teoria de Vigotski}

Diferente das abordagens clássicas de desenvolvimento que entendem o psiquismo humano como algo que o sujeito já traz pronto ao nascer ou como resultado de uma relação passiva com o meio social em que nasce e vive, para a teoria históricocultural, os processos psíquicos surgem nas e das relações sociais de que o sujeito participa. Assim, o aprender, que está, primeiramente, ligado à sobrevivência humana, inclui tanto o desenvolvimento biológico como as conquistas culturais.

Em termos mais amplos, a contribuição de Vigotski remonta a compreensão do ser humano coordenada pela elaboração teórica do desenvolvimento psicológico como um processo histórico, em uma abordagem dialética geral das coisas, a ontogênese e o psiquismo como natureza cultural. Assim, o homem é um ser histórico que se constrói através de suas relações com os meios natural e social, no processo de trabalho (transformação da natureza). É o homem - ao mesmo tempo natureza e história dessa natureza, o que confere a dimensão histórica em uma totalidade em constante transformação, em um sistema dinâmico e contraditório, que necessita ser compreendido como processo de mudanças e de desenvolvimento, portanto, dialético (PINO, 2000).

Ainda na análise realizada por Pino (2000) sobre Vigotski (1997), a natureza cultural do psiquismo está posta sobre a evolução da espécie humana (filogênese) e o desenvolvimento do indivíduo (ontogênese). O conceito de cultura se constitui como "um produto, ao mesmo tempo, da vida social e da atividade social do homem" (VIGOTSKI, 1997, p. 106). Nessa lógica, a cultura pode ser entendida como dimensão da prática social resultante das relações sociais presentes em uma determinada sociedade e, em segundo plano, produto do trabalho. Isso permite a Vigotski enunciar a "lei genética geral do desenvolvimento cultural" (VIGOTSKI, 1997, p. 106), segundo a qual todas as funções superiores ou culturais - em contraposição às funções elementares biológicas - antes de se constituírem no plano pessoal, já existem no plano social ou interpessoal.

As raízes genéticas das duas formas culturais básicas do comportamento são constituídas na idade infantil: o uso de instrumentos e a fala humana Vigotski (1997, vol. 3 e 4). Em 
outros termos isso significa duas coisas: a primeira, que o comportamento humano não é da ordem do biológico, pois suas bases são "formas culturais", por isso suas raízes se constituem na infância e não antes; a segunda, que o que define esse comportamento é ser duplamente mediado, pela técnica e pelo simbolismo. O que quer dizer que, assim como a invenção de instrumentos e de sistemas simbólicos possibilitou aos homens transformar a natureza em cultura e transformam-se eles mesmos de seres naturais em seres culturais (ou humanos, é o mesmo), da mesma maneira, a transformação da criança em um ser humano (ou seja, cultural) pressupõe o acesso dela aos meios que possibilitam essa transformação. Instrumentos e símbolos são os mediadores entre o homem e o mundo, natural e social, que conferem à atividade seu caráter produtivo (PINO, 2000, p. 43).

Nessa premissa, pode-se compreender que a natureza proporciona os materiais que o homem, através trabalho, transforma em função de suas necessidades e, ao mesmo tempo, é transformado por ela. Logo, há um processo dialético no qual o desenvolvimento do homem está intimamente ligado ao desenvolvimento cultural e de sua relação social com o meio em que vive, repercutindo assim em seu conhecimento e em sua leitura de mundo.

É diante dessa base que Leontiev (1978, p. 267) afirma que "cada indivíduo aprende a ser um homem. O que a natureza lhe dá quando nasce não lhe basta para viver em sociedade". É necessário que o indivíduo, no decurso do desenvolvimento histórico da sociedade humana e pelo processo de apropriação da cultura, adquira as aptidões e a própria constituição humana. Isso, por sua vez, está imbuído em um processo dialético no qual as gerações humanas se sucedem e as suas criações passam para as gerações seguintes, sendo multiplicadas e aperfeiçoadas pelo trabalho e pela luta das riquezas que lhes foram transmitidas, passando o testemunho do desenvolvimento da humanidade (LEONTIEV, 1978).

Sob essa ótica se convenciona que o movimento da história só é possível através de transmissão da experiência de vida e de saberes produzidos, em outras palavras, da aquisição da cultura humana para outras gerações. É inerente considerar que nesse processo há uma relação íntima com a comunicação (verbal ou mental), com os instrumentos físicos e simbólicos que foram produzidos ao longo da trajetória dos homens e que, consequentemente, repercute na produção de educação. 
Quanto mais progride a humanidade, mais rica é a prática sóciohistórica acumulada por ela, mais cresce o papel específico da educação e mais complexa é a sua tarefa. Razão por que toda a etapa nova do desenvolvimento da humanidade, bem como no dos diferentes povos, apela forçosamente para uma nova etapa no desenvolvimento da educação [...] Esta relação entre o progresso histórico e o progresso da educação é tão estreita que se pode sem risco de errar julgar o nível geral do desenvolvimento histórico da sociedade pelo nível de desenvolvimento do seu sistema educacional e inversamente (LEONTIEV, 1978, p. 273).

Portanto, o ser humano ao entrar em relação com os fenômenos do mundo circundante através dos seus pares e em um viés comunicacional propicia o desenvolvimento da educação e, por conseguinte se bem organizado pode assegurar um desenvolvimento multilateral e inclusivo repercutindo nas manifestações de uma educação humanizadora e principalmente que se possa compreender e reconhecer o outro dentro de seu processo de construção histórica, humana, social, cultural e diversa.

\section{Organização do ambiente social educativo}

As contribuições da teoria histórico-cultural apontam que o papel da escola é intervir no processo de formação humana e das Funções Psicológicas Superiores (FPS) (pensamento verbal, linguagem oral (fala) e escrita, memória voluntária, autocontrole da vontade, emoção, imaginação, percepção ativa, valores, aptidões, motricidade, atenção ativa, dentre outras) que repercute na constituição das qualidades humanas.

Essa dimensão admite o entrelaçamento entre a linha biológica e a linha cultural (acesso ao patrimônio cultural deixado por outras gerações e pela interação de pessoas mais experientes), o que implica pensar que o ensinar e o aprender compõem uma unidade que delimita o campo de constituição do indivíduo na cultura.

Ao considerar que esse processo está permeado pela aprendizagem, sendo relacionada ao desenvolvimento, é necessário ressaltar que:

[...] o aprendizado adequadamente organizado resulta em desenvolvimento mental e põe em movimento vários processos de desenvolvimento que, de outra forma, seriam impossíveis de acontecer. Assim, o aprendizado é um aspecto necessário e universal do processo 
de desenvolvimento das funções psicológicas culturalmente organizadas e especificamente humanas (VYGOTSKY, 1998, p. 101).

A organização do ensino apresenta essa possibilidade formativa dentro do ambiente escolar, desde que o professor participe ativamente da constituição dos processos psíquicos do aluno. A esse respeito, destaca-se a figura do professor como organizador do ambiente social educativo, o qual deverá ter intencionalidade, planejamento e reflexão (intervenção) para promover o desenvolvimento psíquico (apreensão de conhecimento) dos alunos, à medida que age sobre as funções psíquicas superiores. Nesse processo, o professor, o aluno e o meio são ativos no ato de ensinar e aprender.

As funções psicológicas superiores estariam constituindo o papel de facilitar, se bem mediadas, a apreensão de conhecimento e o processo de construção pelo sujeito, de suas máximas qualidades humanas em interação com os outros e com a cultura através de um movimento dinâmico.

Os professores de classes multisseriadas, em sua grande maioria, concebem várias séries/anos ao mesmo tempo e no mesmo espaço de sala de aula, impulsionando para o desenvolvimento das práticas pedagógicas sob a lógica da seriação, que conduz o professor a elaborar plano de ensino, plano de aula, instrumentos de avaliação pelo número de séries/anos com as quais trabalha. A lógica do sistema engessa os professores, pelas condições que lhes são dadas, a conduzir seu trabalho, fragmentando o conhecimento e, por vezes, através de uma transferência mecânica de cópias e de transcrições de conteúdo do quadro, de livros didáticos que, em grande medida, estão ultrapassados e distantes da realidade dos sujeitos do campo.

É mediante a esse fato que referenciamos a transgressão do modelo seriado de ensino para uma organização do ambiente social educativo em que possa ter intencionalidade, planejamento e reflexão sob o desenvolvimento psíquico, a partir da articulação dos saberes. Isso significa romper com a estruturação curricular, tal como se constitui hoje (fragmentada, urbanocêntrica e estanque), pois planejar é um processo reflexivo que se consolida na práxis educativa quando a ação/atividade humana, entendida 
como princípio educativo, compreende os conhecimentos disciplinares como subsídio à formação do aluno e não o inverso (VASCONCELOS, 2009).

Um processo metodológico que possibilita a construção do conhecimento fundamentada na natureza curricular de ensino e aprendizagem do real vivenciado pelo aluno e professor, conteúdos e áreas do conhecimento em um movimento dialético problematizador, lança críticas sobre a realidade. Nesse ínterim, promove ações educativas que avançam em direção à superação da fragmentação nos processos de produção e de socialização do conhecimento, oportunizando compreensões que contribuem para construir com os alunos da multissérie, uma visão de totalidade dos processos sociais nos quais estão inseridos.

O professor é, necessariamente, o par mais desenvolvido e o responsável pela direção do ensino. A heterogeneidade entre os alunos pode ser potencializadora da aprendizagem, desde que sejam oportunizadas condições planejadas para o compartilhamento do processo de aprendizagem, dado que nos remete à importância das formas de grupalização entre os aprendizes (MARSIGLIA; MARTINS, 2014).

Assim, é imprescindível dimensionar o olhar para a importância do planejamento e da articulação com os pares (grupalização), uma vez que se concebe uma diversidade de pessoas, idades, saberes, modos de vida, memórias coletivas, visões e leitura de mundo, níveis de aprendizagem, dentre outros, que são afirmados nas suas vivências e pela produção de existência, e provocam o desafio de dialogar com a identidade dos sujeitos amazônicos.

Ao atuar com toda essa heterogeneidade, é imprescindível encontrar maneiras de trabalhar com as diferenças, fazendo delas elementos que favoreçam a aprendizagem, bem como, compreender como essas relações se estabelecem dentro do processo interacional.

[...] os diferentes ritmos, comportamentos, experiências, trajetórias pessoais, contextos familiares, valores e níveis de conhecimento de cada criança e do professor imprimem ao cotidiano escolar a possibilidade de troca, de repertórios, de visão de mundo, confrontos, ajuda mútua e consequente ampliação das capacidades individuais (REGO, 1997, p. 88). 
A importância da interação dos sujeitos, para a aprendizagem em aula, propicia uma reflexão a respeito da relação entre desenvolvimento e aprendizagem num processo de interação social, mediada pelo contexto históricocultural de cada realidade (VYGOTSKY, 1989). Dentro dessa perspectiva, a concepção de ensino e aprendizagem envolve os sujeitos que ensinam e os que aprendem. O outro social pode se manifestar por meio de objetos, da organização do ambiente, dos significados advindos do mundo cultural que rodeia o indivíduo e na organização do real e da linguagem.

Nesse contexto, a aprendizagem, como atividade humana, admite um caráter social, tendo seu ápice na relação com o meio em que é impulsionada pela interação com outras pessoas. A escola, nessa perspectiva, deve considerar as ideias e os valores que se encontram no desenvolvimento social e cultural do aluno. Para tanto, é relevante considerar, não só “o meio e as regras que o constituem, mas seu papel e significado, sua participação e sua influência no desenvolvimento" (VIGOTSKI, 2010, p. 682, grifo nosso).

O papel e o significado dos elementos do meio, mediante novas aquisições do processo de desenvolvimento, sofrem modificações e passam a adquirir outros significados e a desempenhar outro papel por força das mudanças ocorridas no ser. A forma como se toma consciência e a apreensão daquilo que ocorre no meio serão elementos importantes para compreender as constituintes da vivência (sujeito + meio $=$ vivência $)$, sendo que mediante a isso se tem a união indivisível das particularidades da personalidade e das particularidades da situação representada na vivência. Logo, o meio desempenha o papel de fonte de desenvolvimento para os sujeitos.

O meio, como complexo variável, relativo e dinâmico, propicia na e pelas relações sociais e, porque não dizer educacional e nas mediações culturais, o desenvolvimento das generalizações superiores (conceitos). Não se pode deixar de considerar que muitas dessas generalizações são compreendidas em partes, processadas, construídas e reconstruídas dentro das idiossincrasias do sujeito.

Essa dimensão dá ao professor a possibilidade de pensar que as funções psicológicas superiores surgem como "formas de comportamento coletivo da criança, 
como formas de cooperação com outras pessoas, e apenas posteriormente elas se tornam funções interiores individuais da própria criança” (VIGOTSKI, 2010, p. 699).

Ao considerar o dinamismo da influência do meio, o professor de classes multisseriadas deve considerar os sujeitos do campo como possuidores de saberes, de memórias coletivas, de simbolismos ligados a terra, à floresta, aos rios, ao trabalho, à sobrevivência, à sociabilidade, aos valores, às identidades culturais e de gênero, construídas de vivências sociais e produtivas. Assim, produzindo a relação de ensino e aprendizagem, à medida que é sujeito e objeto de ensino, seja nas práticas diárias de pescar, de nadar e se deslocar para outros espaços, conhecimentos transmitidos pela educação cultural repassado pelos pais e fortalecido a cada dia com a prática cotidiana.

Dessa forma, compreende-se que a criança apreende conceitos antes mesmo de ingressar na escola, que podem ser denominados de espontâneos ou cotidianos, haja vista que foram concebidos e apreendidos através de suas atividades práticas, o que faz com que o sujeito focalize sua atenção na materialidade do objeto, na ação tangível, repassada pelos seus pares mais experientes, de maneira informal, e que ajudam a compreender esses objetos e/ou fenômenos de seu meio social.

Para compor a atividade cultural, enfatiza-se o saber sistematizado, que não tem a função de substituir outros tipos de conhecimento, como por exemplo, conhecimento do senso comum (saber popular), místico, religioso, em distintos grupos sociais e classes; mas, sim, integrar-se a ele, em um contexto de "uso deliberado, consciente, em situações que se tem clareza dos objetos ou fenômenos que eles representam" (SFORNI, 2010, p. 103). Dessa forma, promovendo a articulação das aquisições de culturas e a nitidez dos objetos referendados pelo que eles representam.

São esferas de conhecimentos que, se bem organizados, com objetivos planejados e intencionais, podem propiciar a tomada de consciência e a apropriação da atividade mental. A preocupação com esses elementos deve ser problematizada na escola, de modo que possa transformar o conteúdo cristalizado na cultura em um produto mental, proporcionado, assim, a internalização dos conceitos e das 
possibilidades de desvelar a realidade, criticar para conhecê-la, recriando o conhecimento e se descobrindo como sujeitos inacabados permanentes.

A aquisição de conhecimento por parte de cada sujeito ocorre por meio da formação de ações e operações intelectuais. Essas ações antes de se transformarem em propriedades internas, de um sujeito em particular, são ações externas presentes na prática social. Isso ocorre no processo de apropriação tanto de instrumentos físicos como simbólicos, tanto na formação de ações e operações motoras, quanto na de ações e operações mentais (LEONTIEV, 1991 apud SFORNI; GALUCH, 2009, p. 121).

Ainda, com base na explicação de Leontiev (1991), na internalização de um instrumento simbólico, as ações e as operações cognitivas são processos que apresentam mais complexidade do que os que ocorrem na apropriação de um instrumento físico ou na aprendizagem de uma ação motora. Assim sendo, nas análises de Sforni e Galuch (2009), para Leontiev a aprendizagem dos instrumentos simbólicos não acontece pelo convívio ou pela experiência imediata: é um processo de educação sistematizada, escolar, que exige intencionalidade e planejamento.

O professor, enquanto organizador do ambiente social do aluno, deve se ater às capacidades reais e às possibilidades de aprendizagem que o educando pode desenvolver com a sua ajuda ou dos demais colegas. Isso é o que se denomina Zona blijaichego razvitia (Zona de Desenvolvimento Iminente).

A zona blijaichego razvitia é a distância entre o nível do desenvolvimento atual da criança, que é definido com ajuda de questões que a criança resolve sozinha e o nível do desenvolvimento possível da criança, que é definido com a ajuda de problemas que a criança resolve sob a orientação dos adultos e em colaboração com companheiros mais inteligentes.

[...] A zona blijaichego razvitia define as funções ainda não amadurecidas, mas que se encontram em processo de amadurecimento, as funções que amadurecerão amanhã, que estão hoje em estado embrionário (VIGOTSKI, 2004, p. 379 apud PRESTES, 2012, p. 204).

A Zona de Desenvolvimento Iminente possibilita ao professor identificar o nível real e possível do aluno e, a partir disso, organizar o meio educativo, constituído no "conjunto das relações humanas" (VYGOTSKY, 2003, p. 79), que podem ocorrer no coletivo e no individual, bem como dimensionar as ações de 
planejamento, de modo a problematizar, questionar e ressignificar criticamente a realidade e o conteúdo/currículo entre os diferentes anos/séries e níveis de aprendizagem. Dessa forma, os conteúdos disponibilizados serão postos à disposição dos alunos, considerando seus tempos e suas formas de aprendizagem.

Para tanto, é preciso pensar em ações metodológicas e recursos que poderão auxiliar na transposição didática, considerando a relação entre os conteúdos e os sujeitos no processo de ensinar e aprender. É uma fase que necessita manter firme a relação com conteúdo, interesses e necessidades dos alunos e, principalmente, com a concepção teórica adotada para a construção do conhecimento, como possibilidade de resistência para não marginalizar as formas de saber e afirmar a inclusão de todos na inteireza de tempos e formas de aprendizagens.

Ao percorrer esse movimento, é necessário propor um processo avaliativo para identificar os conhecimentos produzidos e, portanto, identificar o nível real do aluno e as possibilidades de avanços na aquisição do conhecimento, sob a reflexão crítica da prática.

Nesse processo, cabe ao professor considerar essas concepções para a sua prática pedagógica e, desse modo, integrar o aprendizado e o desenvolvimento histórico-cultural. Assim, "ultrapassar o nível da aparência e buscar a essência de seu trabalho pedagógico, estabelecendo uma relação cada vez mais intencional, critica e reflexiva com sua prática” (TEIXEIRA; MELLO, 2015, p. 10).

Assim, dentro da teoria histórico-cultural é imprescindível que o professor do campo resgate o seu papel na apropriação do conhecimento, à medida que se dedique a desenvolver a organização do ensino, tendo com suporte as vivências, os saberes e a subjetividades dos alunos e do próprio trabalho. Isso na interação e cooperação com os alunos e demais agentes educativos, bem como a intencionalidade de promover novos processos de desenvolvimento através dos conceitos sistematizados.

As relações entre o professor, o aluno e o meio, as representações que se formam ao longo do seu processo histórico e a constituição como seres em transformação são elementos essenciais. Ao transmitir a experiência adquirida, a criação e a recriação que integram a diversidade, as concepções e as práticas 
educativas pensadas para educar e valorizar o indivíduo constituído de direito que merece ser reconhecido em sua identidade, fazem-se necessárias.

\section{Considerações finais}

Os estudos deste artigo, através da reflexão sobre o papel do professor como organizador do ambiente social do aluno em salas multisseriadas, apontam para a atuação de profissionais que exercem a docência com turmas constituídas de várias séries e de alunos com faixa etária e níveis de aprendizagem distintos, o que leva a consternações relacionadas à organização do trabalho pedagógico e à articulação da realidade social da sala de aula.

Ao buscar suporte na teoria histórico-cultural, concebe-se que os processos psíquicos surgem nas e das relações sociais de que o sujeito participa. Assim, o aprender, que está, primeiramente, ligado à sobrevivência humana, inclui tanto o desenvolvimento biológico como as conquistas culturais.

O homem é um ser histórico que se constrói através de suas relações com os meios natural e social, no processo de trabalho (transformação da natureza). Imergido por esse sistema dinâmico, contraditório e dialético, ao longo de seu processo de formação, está sempre produzindo conhecimentos e se apropriando da cultura. E no decorrer da história tem desenvolvido formas de registrar e repassar os conhecimentos, multiplicando e aperfeiçoando, por meio do trabalho, para as gerações seguintes.

A educação é parceira nessa produção e na sistematização de conhecimento, sendo que a escola assume o papel de intervir no processo de formação humana e das funções psicológicas superiores. Isso repercute na constituição das qualidades humanas, para isso demanda a organização do ambiente social do aluno e, o professor, ao assumir essa função deverá ter intencionalidade, planejamento e reflexão (intervenção) para promover o desenvolvimento psíquico (apreensão de conhecimento) dos alunos.

Para o professor que atua em classes multisseriadas é imprescindível dimensionar o olhar para a importância do planejamento e a articulação com os pares (grupalização) na descoberta do saber e na formação das qualidades 
humanas, ao considerar a organização do tempo e espaço em sala de aula. Assim, a dimensão da aprendizagem como atividade humana admite um caráter social, tendo seu ápice no meio, como fonte de desenvolvimento para os sujeitos.

Ao considerar o dinamismo da influência do meio, o professor de classes multisseriadas deve considerar os sujeitos em suas particularidades, da personalidade e da situação representada na vivência, materializando isso na articulação dos conceitos espontâneos e sistematizados com vista a propiciar a tomada de consciência e a apropriação da atividade mental.

O professor, enquanto organizador do ambiente social do aluno, deve se ater às capacidades reais e às possibilidades de aprendizagem que o aluno pode desenvolver com a sua ajuda ou dos demais colegas, valendo-se da zona de desenvolvimento iminente. O papel da escola, enquanto processo de formação humana, abrange a concepção de educação, de homem e de sociedade que se constitui frente à luta para superar o acesso ao conhecimento fragmentado por intermédio de práticas pedagógicas que promovam desenvolvimento e aprendizagem humanizados, em que os conteúdos sejam tratados como meios de conhecer melhor o mundo e as pessoas. Em um processo de ensinar e aprender que valorize e problematize as especificidades e as realidades dos sujeitos, de modo a promover interação entre os saberes.

Nesse sentido, entende-se que a teoria histórico-cultural pode propiciar ao professor, em especial aos de classes multisseriadas, elementos para pensar a prática e ter uma teoria para dar coerência lógica ao trabalho educativo crítico e transformador. Além disso, operar na otimização de possibilidades concretas com as quais se tem no chão de uma sala de aula, alunos de várias séries, distintos níveis de aprendizagem, diferentes idades e que desenvolvem o ensino e aprendizagem em um mesmo espaço e ao mesmo tempo, integrando a diversidade, as concepções e as práticas educativas. Compreende-se que o processo precisa ser pensado para educar e valorizar o indivíduo constituído de direito que merece ser reconhecido em sua identidade. 


\section{Referências}

LEONTIEV, A. N. O Homem e a Cultura. In: O Desenvolvimento do Psiquismo. Lisboa: Livros Horizonte, 1978.

MARSIGLIA, A. C. G.; MARTINS, L. M. Contribuições gerais para o trabalho pedagógico em salas multisseriadas. Nuances: estudos sobre Educação, Presidente Prudente-SP, v. 25, n.1, p. 176-192, jan./abri. 2014. DOI: https://doi.org/10.14572/nuances.v25i1.2725

OLIVEIRA, M. M. Como fazer pesquisa qualitativa. 3. ed. Revista e ampliada. Petrópolis, RJ: Vozes, 2010.

PINO, A. A psicologia concreta de Vigotski: implicações para a educação. In PLACCO, V. M. N. S. (Org.) Psicologia \& Educação: revendo contribuições. São Paulo: EDUC, 2000.

PRESTES, Z. Quando não é quase a mesma coisa: traduções de Lev Semionovitch Vigotski no Brasil. Campinas, SP: Autores Associados, 2012, p. 115-225.

REGO. T. C. Vygotsky. Uma perspectiva histórico-cultural da educação. 4. ed. Petrópolis: Vozes, 1997.

SFORNI, M. S. de F. Perspectiva de formação, definição de objetivos, conteúdos e metodologia de ensino: aportes da abordagem histórico-cultural. In: Paraná. Secretaria de Estado da Educação. Superintendência da Educação. Coordenação de Gestão Escolar. Organização do trabalho pedagógico. Curitiba: SEED, 2010. p. 97-110. (Caderno temático).

SFORNI, M. S. F.; GALUCH, M. T. B. Procedimentos investigativos com base nos pressupostos da teoria histórico-cultural e da teoria da atividade. In: MACIEL, L. S. B.; MORI, N. N. R. (Org.). Pesquisa em Educação: múltiplos olhares. 1. ed. Maringá: EDUEM, 2009, v. 1, p. 117-134.

TEIXEIRA, S. R.S; MELLO, S. M. Formação de professores: uma teoria para orientar a prática, 2015 (No pelo).

VASCONCELLOS, C. S. Currículo: a atividade humana como princípio educativo. 2. ed. São Paulo: Libertad Editora, 2009.

VYGOTSKY, L. S. Psicologia pedagógica. Porto Alegre: Artmed, 2003.

VYGOTSKY, L. S. A formação social da mente: o desenvolvimento dos processos psicológicos superiores. 6. ed. São Paulo: Martins Fontes, 1998.

VYGOTSKY, L. S. Pensamento e linguagem. 2. ed. São Paulo: Martins Fontes, 1989. 
VIGOTSKI, L. S. El significado historico de la crisis de la psicología: una investigación metodológica. In: Obras Escogidas I. Madrid: Visor y Ministerio de Educación y Ciencia, 1991, p. 257-413.

VYGOTSKY, L. S. O papel do meio na pedologia. Psicologia USP. São Paulo, 2010, 21 (4), 681-701. 